This paper is published in the open archive of Mid Sweden University

DIVA http://miun.diva-portal.org

with permission of the publisher

Citation for the peer-reviewed published paper:

Fjellström H, Höglund H, Paulsson M, Rundlöf M. Discolouration of mechanical and chemimechanical pulps : influence of wood raw material, process and ageing method. Nordic Pulp \& Paper Research Journal. $2008 ; 23(1): 14-18$.

URL to article at publishers site:

http://dx.doi.org/10.3183/NPPRJ-2008-23-01-p014-018 


\title{
Discoloration of mechanical and chemimechanical pulps: Influence of wood raw material, process and ageing method
}

\author{
Helena Fjellström and Hans Höglund, Mid Sweden University, Magnus Paulsson, Eka Chemicals AB, Sweden, Mats Rundlöf, Capisco, Sweden
}

KEYWORDS: High-yield pulp, Softwood, Hardwood, Lightinduced, Ageing, Pulping processes, Colour measurements

SUMMARY: The change in colour of different types of unbleached and bleached high-yield pulps under both accelerated and long-term ambient light-induced ageing conditions was studied using the CIELAB colour system. It was found that accelerated ageing conditions that mimic indoor daylight exposure tend to increase mainly the $b^{*}$-value and decrease the $L^{*}$-value (i.e., yellow/darken the pulp). Long-term ambient ageing without indirect sunlight also increases the $\mathrm{a}^{*}$-value, which makes the pulp more reddish. It was also found that accelerated light-induced ageing is characterised by rapid initial discoloration that is followed by a slower, secondary phase. The discoloration caused by long-term ambient light-induced ageing with no indirect sunlight present was more even over time.

ADDRESSES OF THE AUTHORS: Helena Fjellström (helena.fjellstrom@miun.se) and Hans Höglund (hans. hoglund@miun.se): Mid Sweden University, Dept. of Natural Science, Fibre Science and Communication Network, FSCN, Holmgatan 10, SE-851 70 Sundsvall, Sweden. Magnus Paulsson (magnus.paulsson@eka.com): Eka Chemicals AB, SE-445 80 Bohus, Sweden. Mats Rundlöf (mats@capisco.se): Capisco, Nygatan 13, SE-602 34 Norrköping, Sweden. Corresponding author: Helena Fjellström

The major obstacle to the use of mechanical or chemimechanical pulps in high-quality long-life paper products is the rapid brightness reversion that occurs upon exposure to daylight or indoor illumination. These pulps can be produced with lower capital costs and have less impact on the environment than chemical pulps. They also have high yield and bulk, good printing properties, high opacity and light-scattering ability, all of which make it possible to lower the basis weight of the produced paper or paperboard. But all these positive factors are offset by the inferior brightness stability.

When paper from mechanical and chemimechanical pulps is subjected to ultraviolet radiation, chromophores that absorb light in the blue-green region are formed. This discoloration, which leads to a decrease in brightness, is ascribed to the lignin component in the pulp (Gratzl 1985; Heitner 1993; Leary 1994; Davidson 1996; Forsskåhl 2000; Lanzalunga, Bietti 2000). There have been a number of investigations of the type of chromophores that are initially formed, but the results are contradictory. Leary (1968) proposed that the chromophores formed during light-induced yellowing were of the quinone, cyclohexadienone and/or quinone methide types. Lin and Kringstad (1971) suggested, based on lignin model compound studies, that both ortho- and para-quinones can be formed, although the latter to a lesser extent (cf. Lebo et al. 1990). Others suggest that para-quinone structures contribute to the formation of colour during light-induced yellowing (Gellerstedt, Pettersson 1977; Forsskåhl et al. 1991; Hirashima, Sumimoto 1994). This suggestion was supported by Agarwal (1998), who proposed a hydroquinone/paraquinone redox couple as a leucochromophoric/chromophoric system responsible for the discoloration. Hydroxystilbenes have also been proposed as the leucochromophores that are largely responsible for the initial photo-induced discoloration of bleached high-yield pulps (Gellerstedt, Zhang 1993).

There could be many reasons for the discrepancy in these reported results. A high-yield pulp contains a variety of organic compounds, and the complexity of the lignocellulosic system makes it likely that different types of chromophores are formed during light-induced ageing. The discrepancy in the results could also be due to the fact that the studies used different equipments and experimental setups. Moreover, most of the investigations employed accelerated ageing procedures, which sometimes give other results than ageing under conditions closer to the practical everyday situation (Paulsson, Parkås 2001; McGarry et al. 2004; Fjellström et al. 2007).

The brightness stability of high-yield pulps has been reported as differing depending on the wood species and the mechanical pulping processes employed. It has been claimed that hydrogen peroxide bleached chemithermomechanical pulps (CTMPs) are somewhat more prone to yellowing than hydrogen peroxide bleached thermomechanical pulps (TMPs) (Agnemo et al. 1991). However, other investigations (Heitner, Min 1987; Johnson 1989, Johnsson 1991) contradict this finding and report that CTMPs are slightly more stable than TMPs or groundwood pulps and, moreover, that hardwood pulps are more stable than softwood pulps. Paulsson and Ragauskas (1998a) reported that hydrogen peroxide bleached aspen CTMP is more stable under accelerated lightinduced irradiation than dithionite bleached spruce TMP and hydrogen peroxide bleached spruce CTMP, even though the aspen CTMP showed some variation in stability depending on the source of the irradiation.

In addition to the ageing conditions, the optical parameters measured are of the utmost importance when interpreting the ageing characteristics of a pulp. Studies commonly determine the ISO brightness, light absorption coefficient, and post colour number of pulps because these are well-known parameters in the pulp and paper industry. But other optical properties may be of interest when it comes to characterising and understanding the events occurring during light-induced brightness reversion. Several researchers have used the CIELAB system, which displays changes in both lightness and colour, but most of the data reported apply only to acce- 
lerated light-induced ageing conditions (Luo et al. 1988,1989; Andrady et al. 1991; Paulsson, Ragauskas 1998a; Paulsson, Parkås 2000; Ramos et al. 2003). In studies of accelerated ageing, Luo et al. (1988, 1989) demonstrated that the $a^{*}$-value does not change significantly and that brightness reversion results from changes in the $\mathrm{L}^{*}$ - and $\mathrm{b}^{*}$-values. They also used the Vergilbungsvektor $(V V)$, which excludes the $\mathrm{a}^{*}$-value. Paulsson et al. (1996) studied long-term accelerated irradiation of unbleached and hydrogen peroxide bleached spruce TMP. Their general conclusion was that the $\mathrm{L}^{*}$-value decreases and the $\mathrm{b}^{*}$ - and $\mathrm{a}^{*}$-values increase, and that the magnitude of change is more pronounced for hydrogen peroxide bleached pulp. Similar results were later reported for a hydrogen peroxide bleached aspen CTMP (Paulsson, Parkås 2000).

The present study describes the darkening (brightness reversion) characteristics by means of colour changes identified using the CIELAB system. A broad range of unbleached and bleached mechanical and chemimechanical pulps produced from softwood or hardwood on a commercial or pilot plant scale were investigated using both long-term ambient and accelerated light-induced ageing.

\section{Materials and Methods}

\section{Pulp samples}

High-yield pulps, produced on a commercial or pilot plant scale, were used as received for the experiments described in this work. The unbleached and bleached (with dithionite and/or hydrogen peroxide) mechanical or chemimechanical pulps were produced from both softwoods (mainly spruce) and hardwoods (aspen or birch). For more detailed information about the pulp samples, see Fjellström et al. 2007.

\section{Preparation of paper sheets}

Hand-made sheets with a grammage of $60 \mathrm{~g} / \mathrm{m}^{2}$ were prepared according to the SCAN CM 64:00 test method. The paper sheets were conditioned at $23^{\circ} \mathrm{C}$ and $50 \%$ relative humidity before being subjected to either ambient or accelerated light-induced ageing.

\section{Accelerated light-induced ageing}

The accelerated ageing of the paper samples was performed with a Xenotest 150 (Heraeus, Hanau, Germany) equipped with a xenon lamp and with filters (ultraviolet and window glass) that eliminate radiation of wavelengths below $310 \mathrm{~nm}$. The spectral characteristics of the transmitted light are similar to those of average indoor daylight (sunlight behind window glass). For more detailed information about the accelerated ageing procedure, see Fjellström et al. 2007.

\section{Long-term ambient light-induced ageing}

Long-term ambient light-induced ageing was performed by keeping the paper samples in an office environment in which the samples were exposed to light from two Philips TLD 18W/29 warm white fluorescent light tubes placed approximately $0.8 \mathrm{~m}$ above them. The paper samples were exposed to light from the fluorescent lamps for $10 \mathrm{~h}$ per day to simulate an office environment. No indirect sunlight reached the paper samples. More information about the long-term ambient ageing procedure can be found in Fjellström et al. (2007).

\section{Optical measurements}

The optical properties of the pulp sheets were measured using an Elrepho SE 071 spectrophotometer (Lorentzen $\&$ Wettre), the colour of the samples was described using the CIELAB colour system (ISO standard method 5631:2000). During accelerated and ambient ageing the samples were measured after $0,0.5,1,2,4$ and 24 hours and $0,1,3,8,12,15,20,30$ and 52 weeks, respectively. Peroxide bleached birch CTMP and all dithionite bleached pulps were also measured at 40 weeks during ambient ageing.

\section{Results and Discussion}

Figs $1 a-d$ show the change in colour of a large number of high-yield pulps that were subjected to accelerated or ambient light-induced ageing. The abbreviations used in the figures and text below are explained in Table 1. The change in colour during ageing is described using the CIELAB colour system, which is a three dimensional colour space where $\mathrm{L}^{*}$ represents the lightness (or grey scale axis), $a^{*}$ is the red (positive)/green (negative) axis and $b^{*}$ the yellow (positive)/blue (negative) axis. The general effect of ageing is darkening of the pulp (due to stronger light absorption, especially at short wavelengths), which means that $\mathrm{L}^{*}$ decreases upon ageing in a rather similar way for all pulps. It was therefore chosen to represent the change in colour using only the $\mathrm{a}^{*}$ and $\mathrm{b}^{*}$ coordinates in Figs $1 a-d$. Since the ageing behaviour of high-yield pulps produced from hardwoods was different over time, an ambient ageing period of up to 52 weeks was chosen to fully elucidate their behaviour (see Fjellström et al. 2007). Comparable ageing results were obtained after 24 hours of accelerated light-induced ageing for most chemimechanical and mechanical pulps produced from spruce and birch. Note the different scales on the $\mathrm{a}^{*}$ - and $\mathrm{b}^{*}$-axis in Figs $1 \mathrm{a}-d$. The samples were generally more prone to move towards yellow (increase in $b^{*}$-value) in the $a^{*}-b^{*}$ diagram, but there was also a significant change in $\mathrm{a}^{*}$-value (green/red) for most pulps. The comparatively small increase in $\mathrm{a}^{*}$ was clearly

Table 1. Abbreviations used in figures and text.

\begin{tabular}{ll}
\hline Abbreviation & Explanation \\
\hline GWP & Groundwood pulp \\
BGWP & Bleached GWP \\
TMP & Thermomechanical pulp \\
BTMP & Bleached TMP \\
CTMP & Chemithermomechanical pulp \\
BCTMP & Bleached CTMP \\
HTCTMP & High temperature CTMP \\
BHTCTMP & Bleached HTCTMP \\
APMP & Alkaline peroxide mechanical pulp \\
\hline
\end{tabular}



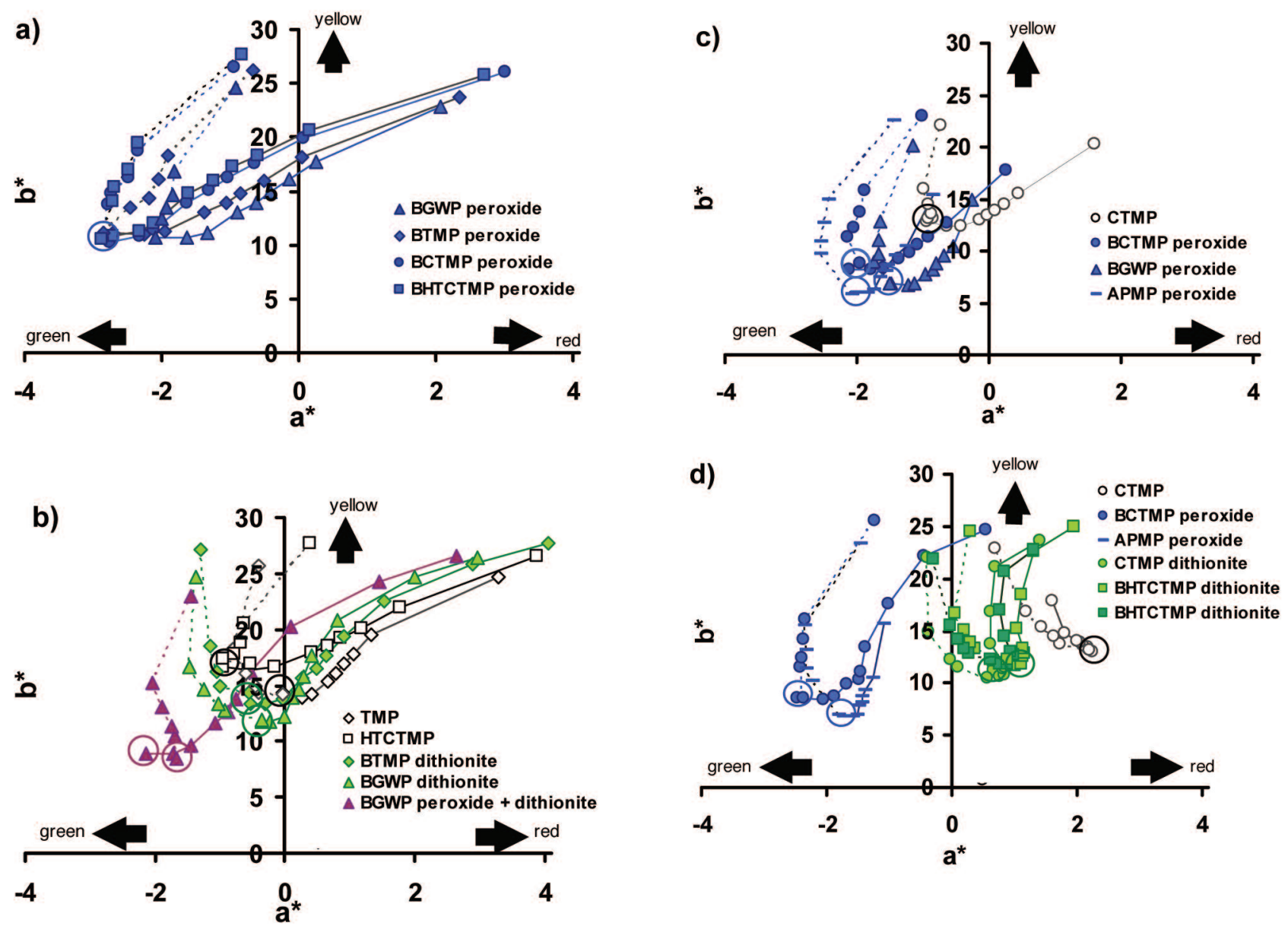

Figs 1a-d. Discoloration of mechanical or chemimechanical pulps a), b) spruce, c) aspen, d) birch monitored over 52 weeks of ambient ageing (solid lines) and 24 hours of accelerated ageing (broken lines). The circled symbols represent the starting points (i.e., unaged paper sheets). The abbreviations used in the figure can be found in Table 1.

visible for the human eye as a more reddish appearance of the sheets.

\section{The influence of light-induced ageing method}

The change in colour during light-induced ageing of high-yield pulps is dependent on the conditions. Fjellström et al. (2007) showed that accelerated lightinduced ageing that mimics indoor daylight exposures can be used to predict the yellowing characteristics of softwood (i.e., spruce) high-yield pulps. This result aligns with the fact that spruce mechanical and chemimechanical pulps finally reach almost the same value on the yellow part of the $b^{*}$-axis regardless of the ageing methods (and bleaching processes) used, see Fig $1 a$ and $1 b$. The accelerated light-induced ageing method more or less had the same impact on all mechanical and chemimechanical pulps studied (see Figs $1 a-d$ ). The b*-value increased (more yellow) and the L*-value (cf. Figs $2 a-b$ ) decreased as expected.

The change in $a^{*}$-value was, however, influenced by the bleaching chemical used. Hydrogen peroxide bleached pulps show at first no change, or a slight decrease in $a^{*}$-value followed by an increase, giving an overall small increase in $a^{*}$-value (i.e., a colour shift towards red). The increase in $\mathrm{a}^{*}$-value was in the range of $1.2-2.2$ and $0.3-1.1$ for the hydrogen peroxide bleached softwood and hardwood pulps, respectively. Dithionite bleached pulps on the other hand showed a small decrea- se in $\mathrm{a}^{*}$-value, i.e. a slight shift towards green. Unbleached spruce TMP and unbleached birch CTMP display the same behaviour as the dithionite bleached pulps. The $\mathrm{a}^{*}$-value of unbleached spruce HTCTMP was increased with 0.92, and unbleached aspen CTMP showed a small increase of 0.12 in a*-value. The discoloration was mainly caused by the pulps turning more yellow and darker, but in addition a smaller but significant change towards red or, in some cases, green could be observed.

The ambient light-induced ageing method revealed three different ageing profiles depending on whether high-yield pulp was produced from spruce, aspen or birch wood. Bleached hardwood high-yield pulps showed a smaller change in $a^{*}$-value $(0.6-3.0)$, especially birch pulps which showed the smallest change, compared to spruce pulps (3.3-5.8). Aspen pulps showed the smallest change in $b^{*}$-value.

Like spruce mechanical and chemimechanical pulps, birch pulps have different colour before ageing, depending on the bleaching method used, but they also have different colour end points as well. Moreover, the behaviour of the $\mathrm{a}^{*}$-value over time for birch is different from that for spruce and aspen. At first, the $\mathrm{a}^{*}$-value increased with time; then there is a phase in which the $\mathrm{a}^{*}$-value is nearly constant; and at the end, after about 30 weeks of ambient ageing, the $\mathrm{a}^{*}$-value increases again, giving the paper a both measurable and visible reddish hue. 
Fjellström et al. (2007) showed that the yellowing tendencies of hardwood high-yield pulps (especially aspen pulps) were overestimated when using an accelerated light-induced ageing procedure. This finding is in agreement with the results in Fig $1 c$, where it can be seen that the $b^{*}$-values from the ambient ageing do not reach the same level as the $b^{*}$-values from the accelerated ageing. There is, however, one exception, the unbleached CTMP, which reaches about the same $b^{*}$-value with both accelerated and ambient ageing. The unbleached aspen CTMP had an initial ISO brightness of $66 \%$ whilst the hydrogen peroxide bleached aspen pulps all had an unaged brightness of at least 78\% ISO and this might be one explanation to the discrepancy in obtained results.

The mechanical pulping process seems to have only a minor impact on the colour change during ageing of both softwood and hardwood pulps, although there are a few exceptions. Stone groundwood pulps are slightly more stable, independent of the bleaching method used. Pulps produced principally from aspen act the same regardless of the pulping process used. It might, however, be possible to identify a slight increase in a* (slightly more red) for the CTMP samples. The birch APMP is distinct from the other birch pulps, and its behaviour is more like that of the aspen pulps. Like aspen, birch APMP displays a smaller change in $b^{*}$-value, they also lack the increase in $\mathrm{a}^{*}$-value at the end of the ambient ageing period. Regardless of the wood raw material used, the alkaline peroxide mechanical pulps had the least change in colour despite having the highest initial brightness.

\section{The phases of light-induced ageing}

Generally, light-induced discoloration is reported to be characterised by a rapid initial phase during which most of the discoloration takes place, followed by a slower, less detrimental phase (Lewis et al. 1945; Francis et al. 1991; Ek 1992). However, the irradiation source is known to influence the appearance of the two phases. Light-induced ageing using low intensity UV/VIS-fluorescent lamps generates a less pronounced initial phase (Paulsson et al. 1998a). Luo et al. (1988, 1989) subjected a bleached groundwood pulp to five hours of accelerated light-induced ageing and observed the typical rapid initial phase for the $\mathrm{L}^{*}$ - and $\mathrm{b}^{*}$-values, followed by a slower phase. According to Andrady et al. (1991), illumination with wavelengths below $400 \mathrm{~nm}$ cause yellowing (higher $\mathrm{b}^{*}$-value, while $\mathrm{a}^{*}$ remain unchanged) and wavelengths above $400 \mathrm{~nm}$ have a bleaching effect (no change in $b^{*}$ and a small change towards greenish in $a^{*}$ ). This finding is supported by Paulsson and Ragauskas (1998b), who used three sets of lamps with different spectral distributions to study accelerated ageing of hydrogen peroxide bleached aspen and spruce CTMP.

Figs $2 a-b$ show the behaviour of hydrogen peroxide bleached CTMPs produced from spruce, aspen or birch when subjected to accelerated or long-term ambient light-induced ageing. The CTMPs are the same pulps as before and can also be found in Figs 1a-d. As previously reported (Fjellström et al. 2007), the initial phase is absent when high-yield pulps are aged under ambient conditions with no indirect sunlight present (Fig 2b). The two ageing phases could, however, clearly be seen for the $\mathrm{b}^{*}$ - and $\mathrm{L}^{*}$-values when the accelerated ageing procedure was used (Fig 2a). The long-term ambient ageing method reveals diverse appearances depending on the wood raw

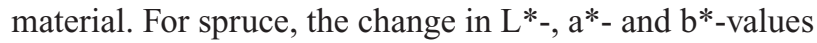
is nearly linear. The first $1-2$ weeks the discoloration of the spruce pulps is due to an increase in a*-value (Figs $1 \mathrm{a}-\mathrm{b})$ whilst the $\mathrm{b}^{*}$-value remains constant. Aspen and birch did not show any change in $b^{*}$-value for the first three weeks. This period was followed by a linear increase in $\mathrm{b}^{*}$-value until week 15 (birch) and week 30 (aspen), after which the increase in $\mathrm{b}^{*}$-value become more pronounced. It may therefore be somewhat misleading to think of light-induced ageing as pure yellowing, indeed on the time scale of a few weeks the pulp may become more reddish before any pronounced increase in yellow begins.

Several suggestions have been made about the type of chromophores that are formed during light-induced ageing of lignocellulosic materials (see Introduction). The chemical composition of the mechanical or chemimechanical pulp, which is dependent on the fibre source (e.g., softwood or hardwood species) and to a lesser extent on the production method (e.g., fibre separation and bleaching processes), will influence the extent of discoloration. In addition, the ageing method itself is of the utmost importance when it comes to the formation of coloured substances.

It is evident from this investigation that high-intensity accelerated and low-intensity ambient light-induced ageing generate either different types of chromophores or different compositions of chromophores as indicated by differences in the CIE $\mathrm{a}^{*}$ - and $\mathrm{b}^{*}$-values obtained.

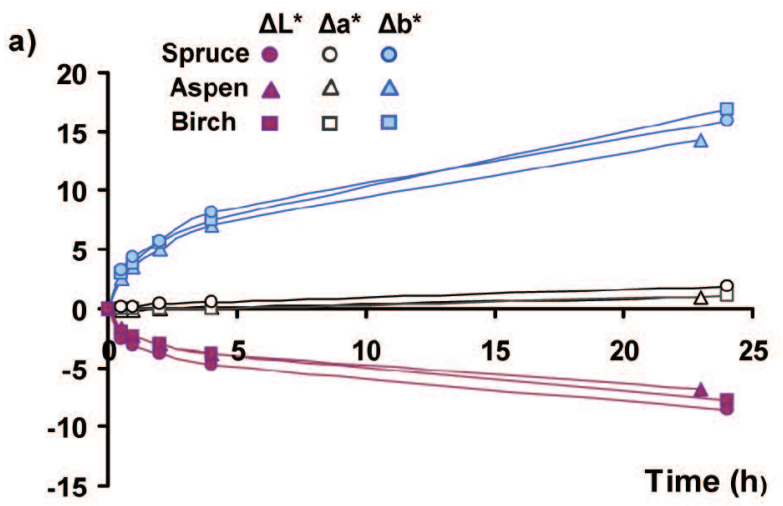

b)

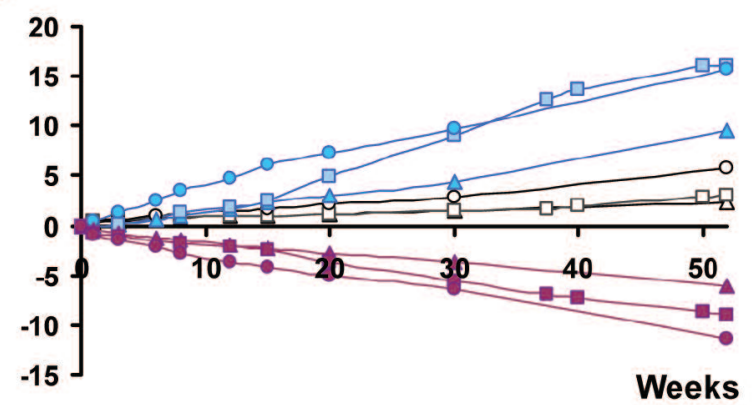

Figs 2a-b. The change (aged - unaged) in $C I E L^{*}-, a^{*}$ - and $b^{*}$-values of hydrogen peroxide bleached spruce, aspen and birch CTMP during a) accelerated lightinduced ageing and b) long-term ambient light-induced ageing. The CTMPs are the same pulps as before and can also be found in Figs 1a-d. The unaged brightness of the CTMPs was in the range of $76-79 \%$ ISO. 
Ambient ageing tends to generate coloured substances that have absorption at higher wavelengths than the chromophores generated during accelerated ageing. This finding underscores the importance of using the right experimental set-up when evaluating the mechanism of light-induced ageing or the photo-stability of untreated, additive-treated or chemically modified high-yield pulps. Using the right ageing method is also important when choosing the proper mechanical or chemimechanical pulp for a particular end-product.

\section{Conclusions}

Using the CIELAB colour system to investigate the change in colour of different types of unbleached and bleached high-yield pulps revealed considerable diversity between the results obtained under accelerated and longterm ambient light-induced ageing conditions. Accelerated ageing conditions that mimic indoor daylight exposure tend to increase mainly the $b^{*}$-value and decrease the $L^{*}$-value (i.e., yellow the pulp), whereas long-term ambient aging with no indirect sunlight present also increases the $\mathrm{a}^{*}$-value, which makes the pulp more reddish. Long-term ambient light-induced ageing causes a continuous discoloration over time, whilst accelerated light-induced ageing is characterised by rapid initial discoloration followed by a slower, less detrimental secondary phase. Softwood pulps display a greater change in $\mathrm{a}^{*}$-value than hardwood pulps, which on the other hand shows a less linear increase with time. Papers produced from alkaline peroxide mechanical pulps display the smallest change in colour, making them suitable for use in long-life paper and paperboard products.

\section{Acknowledgements}

The authors would like to thank SCA Graphic Research AB, Sundsvall, for their support. The financial support of the Fibre Science and Communication Network (FSCN), EU Objective 1, the Region of South Forest Counties, The Knowledge Foundation and The Swedish Energy Agency is gratefully acknowledged.

\section{Literature}

Agarwal, U.P. (1998): Assignment of the photoyellowing-related $1675 \mathrm{~cm}^{-1}$ Raman/IR band to $p$-quinones and its implications to the mechanism of color reversion in mechanical pulps, J. Wood Chem. Technol. 18(4), 381-402.

Agnemo, R., Francis, R.C., Alexander, T.C. and Dence, C.W. (1991): Studies on the mechanism of the photoyellowing of bleached mechanical and chemimechanical pulps. III. The role of hydroxyl radicals, Holzforschung, 45(Suppl.), 101-108.

Andrady, A.L., Song, Y. and Parthasarathy, V.R. (1991): Photoyellowing of mechanical pulp. Part 1: Examining the wavelength sensitivity of light-induced yellowing using monochromatic radiation, Tappi J. 74(8), 162-168.

Davidson, R.S. (1996): The photodegradation of some naturally occurring polymers, J. Photochem. Photobiol. B 33(1), 3-25.

Ek, M. (1992): Some aspects on the mechanisms of photoyellowing of high-yield pulps, Ph.D. thesis, the Royal Institute of Technology, Stockholm, Sweden.

Fjellström, H., Höglund, H. and Paulsson, M. (2007): Light-induced yellowing of mechanical and chemimechanical pulp sheets: influence of wood raw material, process and ageing method, Nord. Pulp Paper Res. J. 22(1), 117-123 and Nord. Pulp Paper Res. J. 22(2), 275 (Erratum).

Forsskåhl, I. (2000): Brightness reversion, In: Stenius, P. (ed.), Forest Products Chemistry, Fapet Oy, Helsinki, Finland, pp. 278-332.

Forsskåhl, I., Tylli, H., Olkkonen, C. and Janson, J. (1991): Photochemistry of quinones and hydroquinones on solid matrices, 6th Int. Symp. Wood Pulp. Chem., Melbourne, Australia, April 29-May 3, APPITA, Carlton, Australia, Vol. 2, pp. 255-262.

Francis, R.C., Dence, C.W., Alexander, T.C., Agnemo, R. and Omori, S. (1991): Photostabilization of thermomechanical pulps by alkylation and borohydride reduction, Tappi J. 74(12), 127-133.

Gellerstedt, G. and Pettersson, E.-L. (1977): Light-induced oxidation of lignin, Part 2. The oxidative degradation of aromatic rings, Svensk Papperstidning, 80(1), 15-21. Gellerstedt, G. and Zhang, L. (1993): In: Heitner, C. and Scaiano, J.C. (eds.) Photochemistry of Lignocellulosic Materials, ACS Symposium Series 531, Washington, DC, USA, Chapter 10, pp. 129-146.

Gratzl, J.S. (1985): Lichtinduzierte Vergilbung von Zellstoffen - Ursachen und Verhütung, Papier 39(10A), V14-23.

Heitner, C. (1993): Light-induced yellowing of wood-containing papers: An evolution of the mechanism, In: Heitner, C. and Scaniano, J.C. (eds.), Photochemistry of Lignocellulosic Materials, ACS Symposium Series 531, Washington, DC, USA, pp. 2-25. Heitner, C. and Min, T. (1987): The effect of sulphite treatment on the brightness and bleachability of chemithermomechanical pulp, Cellul. Chem. Technol. 21(3), 289-296. Hirashima, H. and Sumimoto, M. (1994): A basic chromophore and leucochromophore in mechanical pulps: possible repetition of photochemical reduction-oxidation-reduction, Tappi J. 77(1), 146-154.

Johnson, R.W. (1989): Brightness stability of mechanical pulps: Relating laboratory data to performance, Tappi J. 72(12), 181-187.

Johnson, R.W. (1991): CTMP in fine papers: On-machine surface treatments for improved brightness stability, Tappi J. 74(5), 209-217.

Lanzalunga, 0. and Bietti, M. (2000): Photo- and radiation chemical induced degradation of lignin model compounds, J. Photochem. Photobiol. B 56(2-3), 85-108.

Leary, G.J. (1968): The yellowing of wood by light: Part 2. Tappi, 51(6), 257-260. Leary, G.J. (1994): Recent progress in understanding and inhibiting the lightinduced yellowing of mechanical pulps, J. Pulp Paper Sci. 20(6), J154-J160.

Lebo, S.E., Lonsky, W.F.W., McDonough, T.J., Medvecs, P.J. and Dimmel, D.R. (1990): The Occurrence and Light-Induced Formation of ortho-Quinonoid Lignin Structures in White Spruce Refiner Mechanical Pulp, J. Pulp Paper Sci. 16(5), J139-J143.

Lewis, H.F., Reineck, E.A. and Fronmuller, D. (1945): The "fading" of groundwood by light. I. A study on the relation between the variables in sheet formation and fading, Paper Trade J. 121(8), 44-48.

Lin, S.Y. and Kringstad, K.P. (1971): Some reactions in the photoinduced discoIoration of lignin, Norsk Skogsind. 25(9), 252-256.

Luo, C., Putz, H.-J. and Göttsching, L. (1988): Untersuchungen zur licht- und hitzeinduzierten Vergilbung von gebleichten ligninhaltigen Primär- und Sekundärfaserstoffen, Papier, 42(10A), V55-V67.

Luo, C., Putz, H.-J. and Göttsching, L. (1989): Zusammenhänge zwischen optischen Kenngrössen zur Beurteilung der Vergilbung von Holzstoffen, Papier, 43(10), 537-548. McGarry, P.F., Schmidt, J. and Heitner, C. (2004): Accelerated light exposure of wood containing pulps. Part I: Effects of wavelength and intensity, Tappi J. 3(10), 18-24.

Paulsson, M., Simonson, R. and Westermark, U. (1996): Chemical modification of lignin-rich paper. Part 5: Long-term irradiation of unbleached and hydrogen-peroxide-bleached acetylated spruce TMP, Nord. Pulp Paper Res. J. 11(4), 227-233.

Paulsson, M. and Ragauskas, A.J. (1998a): Chemical modification of lignin-rich paper. Part 8: Effect of light source on the accelerated light-induced yellowing of untreated and acetylated high-yield pulps, Nord. Pulp Paper Res. J. 13(2), 132-142.

Paulsson, M. and Ragauskas, A.J. (1998b): Chemical modification of lignin-rich paper. Part 10: The light-induced yellowing of untreated and acetylated high-yield pulps studied by solid-state UVNIS diffuse reflectance spectroscopy, Nord. Pulp Paper Res. J. 13(2), 198-205.

Paulsson, M. and Parkås, J. (2000): Chemical modification of chemimechanical pulps. Part 1: Mechanical, optical, and aging properties of propionylated spruce CTMP, J. Wood Chem. Technol. 20(2), 205-224

Paulsson, M. and Parkås, J. (2001): Long-term natural aging of untreated and chemically modified high-yield pulps, 11th Int. Symp. Wood Pulp. Chem., Nice, France, June 11-14, ATIP, Paris, France, pp. 227-230.

Ramos, J., Paulino, L., Turrado, J., Davalos, F., Riviera, J. and Young, R. (2003): Surface treatment of chemimechanical pulp (CTMP) to prevent brightness reversion, Cellul. Chem. Technol. 37(1-2), 95-115.

Manuscript received October 23, 2007 Accepted November 29, 2007 